\title{
Women's perceptions of contributory factors for not achieving a Vaginal Birth after Caesarean (VBAC)
}

\section{Authors}

Georgina KELLY BN, PG Dip Mid

Graduate Registered Midwife

Department Nursing and Midwifery Education and Research

King Edward Memorial Hospital

Bagot Road

Subiaco, Western Australia

Email: georgina.kelly@ health.wa.gov.au

Yvonne HAUCK RN, RM, BScN, MSc, PhD

Professor of Midwifery

Curtin University and King Edward Memorial Hospital

Curtin Health Innovation Research Institute

Perth, Western Australia

Email: y.hauck@curtin.edu.au

Sara BAYES RN, RM, Dip Nurs, PG Dip Mid, M Mid, PhD

Research Implementation Fellow

Collaboration for Leadership in Applied Health Research and Care - Nottinghamshire,

Derbyshire and Lincolnshire,

University of Nottingham,

England, UK and

Adjunct Midwifery Research Fellow,

Curtin University

Curtin Health Innovation Research Institute

Perth, Western Australia

Email: sara.bayes@nottingham.ac.uk

Tasmin HARDWICK BN, PG Dip Mid

Clinic Midwife, Next Birth After Caesarean Clinic

King Edward Memorial Hospital

Bagot Road

Subiaco, Western Australia

Email: tasmin.hardwick@health.wa.gov.au

\section{Acknowledgements}

We would like to acknowledge the women who kindly shared their pregnancy and birth experiences whilst attending the NBAC clinic. 


\section{Women's perceptions of contributory factors for not}

\section{Abstract} achieving a Vaginal Birth after Caesarean (VBAC)

Background: With caesarean rates around the world escalating, concern is growing around why women wanting a vaginal birth after caesarean (VBAC) are not achieving their goal. Aim: To gain an understanding of women's perceptions of factors they felt contributed to not achieving a VBAC.

Setting and participants: Fifteen women were interviewed following a non-elective repeat caesarean section (NERCS). They had attended a Western Australian midwifery led service, Next Birth After Caesarean (NBAC), and laboured but were not successful in achieving a VBAC due to reasons around delayed progress. Interview transcripts were analysed using Colaizzi's method of thematic analysis.

Findings: Five themes emerged: 'Tentative commitment with lingering doubts', 'My body failed me', 'Compromised by a longer than tolerable labour', 'Unable to effectively selfadvocate in a climate of power struggling and poor support' and 'The inflexibility of hospital processes'. The final theme included two subthemes, 'Restrictive policies' on labour and use of the cardiotocograph, 'The CTG'.

Conclusions: When labour did not progress as envisaged and hospital processes adversely affected how women were supported, women's doubts around being able to achieve a VBAC were reinforced with a NERCS. Maternity services need to ensure clinical practice reflects best evidence whilst assuring staff are supportive of women's choice.

Key words: VBAC, qualitative evaluation, childbirth, perception 


\section{Background}

From the introduction of oral contraceptive to the use of in vitro fertilisation and genetic technologies, the past century has seen exponential advances in fertility and associated childbearing choices. In stark contrast over the same period is the decline in spontaneous vaginal births. According to the Australian Bureau of Statistics spontaneous vaginal births, excluding assisted vaginal births, in Australia have dropped from 68\% in 1991 to $59 \%$ in 2004 whilst caesarean section (CS) has grown from 18\% to 29\% (Linacre, 2007). The story is similar in other developed countries. In the United States (US) in 1965, the rate of CS was less than 5\%, however this birth mode now accounts for over $30 \%$ of US births (Guise et al., 2010). Similarly, the United Kingdom's CS rate is at an all-time high of $24.8 \%$ (The Information Centre for Health and Social Care, 2012).

The increase in CS is further compounded by the fact that one CS predisposes women to a further operative birth in subsequent pregnancies. Despite the World Health Organisation (World Health Organization, 1985) and many medical professional bodies endorsing vaginal birth after caesarean (VBAC) for the majority of women with one previous CS (American College of Obstetricians and Gynecologists, 2010; Royal Australian and New Zealand College of Obstetricians and Gynaecologists, 2010; Royal College of Obstetricians and Gynaecologists, 2007), birth statistics across the developed world indicate that for most women with a previous CS, elective repeat caesarean section (ERCS) remains the dominant mode for subsequent births (Li, McNally, Hilder, \& Sullivan, 2011; The Information Centre for Health and Social Care, 2012). Even though VBAC has been calculated as a feasible birth mode for 60 to $80 \%$ of women, VBAC rates remain low (Guise, et al., 2010). Australian birth statistics suggest that numbers of maternity health professionals who are supportive of women who prefer VBAC are relatively low (Li, et al., 2011), although measures are being taken to improve availability of this choice. In New South Wales, the Health Department has directed its services to reduce their caesarean section rates (NSW Government, 2010), whilst the tertiary maternity service for the state of Western Australia introduced a 'Next Birth after Caesarean' clinic in 2008 with a similar aim (Government of Western Australia: Department of Health, 2009).

Reluctance among health professionals to support VBAC has been related to the risk of uterine rupture (Wells, 2010). This is despite a comprehensive body of work supporting the overall increased safety of VBAC relative to uterine rupture and other risks of ERCS for women and babies (Guise, et al., 2010; Hruban et al., 2012; Lydon-Rochelle, Cahill, \& 
Spong, 2010; Macones et al., 2005; Wen et al., 2004). Risks associated with VBAC are reportedly similar to those associated with vaginal birth in a first labour (Rozen, Ugoni, \& Sheehan, 2011) and maternal morbidity rates in VBAC are comparable to those associated with elective CS (Grobman et al., 2009). Nonetheless, in 2009, 87\% of Western Australian women with a previous CS were recorded as having a repeat CS with similar rates of $86.3 \%$ in 2010 (Joyce \& Hutchinson, 2012; Joyce \& Tran, 2011).

Being supported during pregnancy to pursue a VBAC is one contributor to the likelihood of achieving a successful VBAC. Even so, studies have highlighted other factors, such as previous VBAC and spontaneous labour may increase the likelihood of a successful VBAC (Madaan, Agrawal, Nigam, Aggarwal, \& Trivedi, 2011). The risk for an unsuccessful VBAC is associated with labour induction, dystocia, and maternal obesity (Landon et al., 2005). Whilst useful in terms of outcome prediction (Grobman et al., 2009; Guise et al., 2010), these quantitative studies have had limited impact on decreasing CS rates, confirming the need for further investigation. A recent collaborative review of the body of evidence concerning VBAC by the US National Institutes of Health (Cunningham et al., 2010), highlighted how intrapartum factors may be affecting VBAC rates and recommended further investigation into this aspect of care. A Cochrane systematic review on the subject similarly suggests that contributory factors influencing CS warrant additional research (Khunpradit et al., 2011).

Qualitative studies reporting women's perceptions in relation to VBAC have concentrated on their decision-making (Meddings, Phipps, Haith-Cooper, \& Haigh, 2007; Penso, 1994) and postnatal reflections of their birth experience (Fawcett, Tulman, \& Spedden, 1994; Fenwick, Gamble, \& Mawson, 2003). Women's dissatisfaction with their childbirth experience implicating CS has also been described (Chigbu, Enwereji, \& Ikeme, 2007; Dahlen \& Homer, 2011). Nevertheless, we have limited understanding of women's perceptions of what they feel influenced their desired VBAC becoming a non-elective CS.

\section{Method}

\section{Research Design}

The aim of this study was to gain an understanding of women's perceptions of factors they felt contributed to not achieving their desired VBAC. To capture women's perspectives of their birth experiences, a descriptive qualitative design was chosen (Polit \& Beck, 2010). Qualitative research focuses upon the subjective description and interpretation from participants words to gain rich data and insight into an understanding of human experiences (Liamputtong, 2010; Taylor, Kermode \& Roberts, 2007). 


\section{Participants and setting}

The participants were drawn from the Next Birth After Caesarean (NBAC) service which was set up at King Edward Memorial Hospital (KEMH) in 2008. As the only public tertiary maternity hospital in Western Australia, KEMH accommodates around 6000 births annually, and cares for the majority of high risk pregnancies within its obstetric led model of maternity care. The NBAC clinic offers a midwifery led antenatal service as an alternative for women who have had a previous caesarean birth (KEMH, 2011). To facilitate continuity, a core group of three midwives see the women at all visits, excluding 24 and 36 weeks gestation where they are examined by a medical officer in the mainstream antenatal clinic. NBAC midwives provide continuity within the antenatal period only and at this stage are not able to follow women through the intrapartum or postpartum period. The clinic promotes informed choice; women who want to pursue either a VBAC or an ERCS are accepted. From January 2009 to December 2011, 621 women attended the NBAC clinic during their pregnancy. Of these women, 198 (31.9\%) achieved a VBAC, 237 (38.2\%) chose an ERCS and 186 (29.9\%) experienced a non-elective repeat caesarean section (NERCS).

Inclusion criteria included women attending the NBAC service who were English speaking, chose to pursue a VBAC in their most recent pregnancy and commenced labour but experienced a non-elective CS primarily due to a delay in labour progress. All women had their NERCS between the months of October 2010 and September 2011. During this 12 month study period, 53 NBAC women had a NERCS, of whom 31 met our inclusion criterion of primary delayed progress. Details of women who met the inclusion criteria were obtained from the NBAC service records who were then invited to participate in our study.

\section{Recruitment and data collection}

Women were recruited by telephone, and informed about the study and the approximate time commitment to participate in a telephone interview. Eighteen of the potential 31 women were contacted; three declined. As data saturation was obtained with 15 interviews, the remaining 13 potential participants were not contacted. Semi-structured individual in-depth telephone interviews (between September and December 2011) allowed for flexibility in sharing of birth experiences and elaboration of women's responses (Schneider, Whitehead, Elliott, Lobiondo-Wood, \& Haber, 2007). Open ended questions were utilised to explore the participant's perspective surrounding what they felt contributed to not achieving a VBAC. During the interview, participants were asked prompting questions around a focal question: "What do you feel influenced your recent birth becoming another caesarean"? 


\section{Data analysis and trustworthiness}

Data analysis of the verbatim transcripts was undertaken by a team of four midwives utilising Colaizzi's method to capture and describe the women's experiences. The descriptive, qualitative design following Colaizzi's procedures was well suited to gain an understanding of these women's perceptions (Schneider, et al., 2007). This method included: reviewing all data, extracting key statements and concepts, then further refining and organising data into similar groupings (Polit \& Beck, 2010). From this process, a list of preliminary categories and potential themes emerged which were refined through collaboration between the research team members to confirm the final themes and subthemes. All team members analysed the transcripts independently prior to coming together to debate and finalise themes. The team was comprised of two research midwives and two clinical midwives. The participants' perception of the factors around their not achieving a VBAC was summarised within emergent themes with supportive quotes. Recruitment ceased when data saturation was reached (Schneider, et al., 2007); preliminary saturation occurred after 13 interviews, with two further interviews conducted to confirm saturation.

\section{Ethical considerations}

Ethical approval was obtained from the WA Women and Newborn Health Service Human Research Ethics Committee (Number 2582). All women were informed of the study aim when invited to participate and confirmed their willingness to having the interviews digitally recorded. Verbal consent was obtained over the telephone. The midwife who conducted the interviews was not involved in any midwifery care or contact with the participants prior to the interview. All data is recorded on a password protected computer in accordance with the National Health and Medical Research Council guidelines (National Health and Medical Research Council, Australian Research Council, \& Committee, 2007) and will be retained for 5 years.

Due to the topic sensitivity, some women during their interviews demonstrated distress as their voices broke or trembled. Others expressed anger. At the completion of the interviews, all participants were informed of support services available to them within the health service and the wider community such as the KEMH Department of Psychological Medicine, the NBAC service telephone debriefing, and the peer support group 'Birthrites: Healing After Caesarean'.

\section{Findings}

Fifteen NBAC women who expressed a desire for a VBAC but experienced a NERCS in their recent pregnancy were interviewed. Participants' age ranged from 25 years to 39 years 
old (mean 31 years) and were married or in a de facto relationship. All women experienced labour either of spontaneous onset $(n=13)$ or as a result of induction $(n=2)$ but due to a primary delay in progress of their labour had a NERCS. In addition to this delay in labour progress, fetal distress was also noted for three participants. Documented labour ranged from 3 hours 14 minutes to 25 hours 12 minutes with an average just over 12 hours. The average infant birth weight was $3.82 \mathrm{~kg}$, with all but one infants' birth weight being above the Australian average of $3.37 \mathrm{~kg}$ (Linacre, 2007). Further labour and birth information as well as a summary of recognised risk factors for unsuccessful VBAC by our participants (Royal College of Obstetricians and Gynaecologists, 2007) are provided in Tables 1 and 2. Of the 15 risk factors associated with not achieving a VBAC, only four were related to the majority of our participants: 15 had not experienced a previous VBAC, 14 had never experienced a vaginal birth, 13 presented with a cervical dilatation of less than $4 \mathrm{~cm}$ at admission, and for 10 women their previous CS was related to dystocia.

Five themes emerged during data analysis: 'Tentative commitment, lingering doubts', 'My body failed me', 'Compromised by a longer-than-tolerable labour', 'Unable to effectively self-advocate in a climate of power-struggling and poor support' and 'The inflexibility of hospital processes' (Table 3). Direct quotes have been used to illustrate women's stories and participant numbers (P1-15) have been used to protect their privacy.

\section{Tentative commitment, lingering doubts}

This theme depicts the residual degree of uncertainty about the likelihood of achieving a VBAC that persisted for many of our participants regardless of anything else that happened to influence their eventual mode of birth. For many, uncertainty and doubts were always there: I mean I went in with the expectation that I would not be successful ... Just the statistics ... I knew that I probably would not be successful if I tried (P5). In some cases these seeds of doubt were planted during women's antenatal clinic visits by medical staff: P4's experience was that, She [doctor] said a couple of comments that sort of depleted my confidence about having a natural birth. P9 was advised by the doctor she saw that, "[vaginal birth] ain't gonna happen and, if it... it's up to basically us to make it happen for you", which she went on to describe as, very disempowering and I didn't like that very much, though probably realistic.

For those whose labour didn't get underway spontaneously and for those in whom labour was slow to progress, this reinforced their conviction that they wouldn't be able to do it: I probably completely lost hope when ... after they ruptured my membranes I didn't go into labour ... I felt like it was all going downhill from that point on 'coz I knew that it was just intervention after intervention was going to happen (P1). 
For some participants, doubt about the likelihood of giving birth naturally was related to their own ambivalence. For these women, having the opportunity to attempt labour and being enabled to pursue a vaginal birth this time was reported to be important. In addition, actually giving birth vaginally came with a number of caveats and so consequently, when labour did not progress as envisaged, the decision for a repeat caesarean was made fairly easily, especially when multiple personal conditions were met. P2 provided an example when she said, I thought "ok, because there's a few factors, it's not just, oh the baby's stuck” (P2). Whilst they had consistently verbally expressed a desire to have a vaginal birth, some participants subsequently confessed relief when it was decided that a CS would be necessary. P8, for instance, said The fact that it ended up in a caesar[ean] didn't really bother me because I was quite scared of having a natural birth anyway.

Motivation for a VBAC among these women varied; some shared how they attempted it to please themselves and/or others and that for them, attempting a labour that was not successful with a VBAC was enough to satisfy societal and personal expectations. Others said that as a VBAC had been medically approved, they felt obliged to attempt it. Some said they wanted to experience labour to say that they'd done it, and others said it was about being given a choice that they did not have with their previous CS. Many commented on being underprepared for labour and on their subsequent reliance on medical opinion when deviations from accepted norms occurred during their birthing episode.

\section{My body failed me}

The narratives of most of our participants contained references to their body's lack of capacity to labour and give birth naturally. For example, two women were discouraged when they did not commence labour spontaneously and were induced for being over 40 weeks gestation. Many women took ownership of this perceived failure with statements such as: $I$ don't dilate (P1), my cervix is really slow and...won't open $(\mathrm{P} 4)$, and that there was not a great fit... through my pelvic canal (P2). If they could have influenced any change in their birthing experience they suggested that they would get a new cervix (P4) or alter the shape of my pelvis (P3) as the fault was what my body did and not what anyone else there did (P8). From pelvic shape, cervical behaviour, genetics (P10), and physiology (P4), the conviction that their body failed them was a common feature in women's perception of why they did not achieve a VBAC. For four women, the interplay between the baby and their own body was the issue: these women described being unable to physically facilitate the passage of a 'posterior' baby: 
The baby being posterior was probably the main thing. I mean now there's no denying after 30hrs of labour if you've only dilated $2 \mathrm{cms}$ and or $3 \mathrm{cms}$ or whatever it was...(P9).

Some women also shared how their labour went on longer than expected: 28 hours ... and still hadn't dilated much (P4). On arrival to hospital most participants were assessed as not in established labour as per hospital guidelines. Some expressed their disappointment when minimal progress was being made despite painful contractions.

Interestingly, for some women this realisation was healing. Some participants suggested that being able to isolate their body as a main causative factor for not achieving a VBAC this time enabled them to resolve feelings of failure and blame they had harboured about their first CS: It healed a lot that we had hanging over us from the first birth (P3).

\section{Compromised by a longer-than-tolerable labour}

Data analysis confirmed that participants experienced unmet expectations around their ability to tolerate a natural labour that progressed beyond the limits deemed acceptable to the hospital. Regardless of whether labour was considered established or not, the enormous challenge of enduring painful contractions for a prolonged time was a common feature of the stories. Participants expressed how experiencing that much pain just affects your decision making and your resilience (P4). As P10 stated: when you're in that situation where you're in pain and stuff like that you just go with the flow. Exhaustion and tiredness affected women's decision making and ability to advocate for what they wanted: I think even if I had suddenly dilated and continued with things I don't think I would've had the energy to actually kind of get right through labour (P2). Some women described how interventions were introduced to accelerate the labour with the goal of meeting partogram guidelines. These interventions limited access to labour care options such as showers and baths resulting in women submitting to more medical options: tends to lean you toward more like medical interventions like drugs and the epidural (P1). As labour did not progress as anticipated and time slowly passed by, women's doubts in their own physical ability became more evident:

I was still only 2-3cms despite having laboured all morning in great pain and I tried showers, walking around, everything, but you know nothing really worked, so I opted to have an epidural and I'd even said to them "look um I'll have the epidural but can you schedule me in for a c-section as well” because I just thought this labours never going to happen by itself, you know I'd already been in labour for well over 24 hrs and I was exhausted (P4)

Unable to effectively self-advocate in a climate of power struggling and poor support 
Comments made by women concerning their inability to advocate for themselves during labour, and the part that caregivers' support, or lack thereof, played are captured in this theme. As noted previously, midwives from the NBAC service did not care for these women during the intrapartum period. In the main, participants felt their self-advocacy was limited, and that this resulted in their being readily influenced by and accepting of the opinion of others: The example P11 gave is as follows: At 22hours they said "look, I think you've pretty much had enough"; I'd dilated to 6cms and wasn't really going anywhere fast and they said for my safety and the baby's safety it would probably be best for a Caesar[ean].. And...I was thinking that's the right thing to do.

For some women, their previous childbirth experience(s) left them fearing being alone in labour, and so they paid for a personal support person to stay with them. Doulas were employed by four of the 15 participants who described feeling unable to 'manage' a VBAC on their own: I hired a doula as well, sort of to talk over what had happened last time so Ifeel like I'd already come to terms with the fact that I might have a caesarean again (P14). The presence of a doula did seem to the women to influence labour and birth suite midwives' behaviour; these participants reflected on how the midwives did not remain in the room and that they were often left alone with the doula.

Some participants experienced caregivers they perceived as not ideal in that they would not 'work with' women's intrapartum needs and wants. One participant recalled $I$ remember fighting with the midwife because I really wanted to have a shower and she wouldn't let me off the monitor (P9). Some women lamented staff not respecting their desire for non-pharmacological pain management: no natural pain relief was ever offered like in terms of heat packs or anything. It was, yeah, that was a bit disappointing really (P1). The intrapartum experience for women was heavily dependent on the personality and approach of the midwife allocated to them on the day; The midwives, you don't know them, so you have no emotional support and Ifound them quite off-standish (P1). Not having any 'connection' to or being known by the midwife influenced the women's determination in pursing their desired VBAC. Some participants found their experience disappointing but were reluctant to implicate their caregivers: It's not to say they were bad midwives, it's just for what I needed I didn't get the support I would've liked (P9). It was felt that some midwives demonstrated their not being receptive to women's needs by returning to the labour room to yell (P9) at them for changing positions or leaving participants alone who were afraid: I didn't really know what I was doing and I was scared that something would happen while she [midwife] wasn't there (P5). 


\section{The inflexibility of hospital processes}

The final theme that emerged from the analysis of our data also included two subthemes, namely 'Restrictive policies' and 'The CTG'.

\section{Restrictive policies}

Women perceived that VBAC clinical guidelines could negatively influence their chance of achieving a VBAC depending upon how strictly they were enforced: I found them [midwives] to be very much interested in the protocols of the hospital and doing what was right by the hospital but not doing much to help facilitate a natural birth (P9). Some participants expressed frustration with restrictions placed on them resulting in few options to 'naturally' manage pain and limited movement. For example, having an intravenous infusion limited opportunities to use water for pain management or be freely able to walk around. Time limits around labour progress were affected by how busy the labour suite was in being able to promptly offer augmentation which then extended the length of labour: no rooms available on the labour ward (P2). Participants shared how they were told to come straight in as soon as you're having contractions (P8) rather than waiting until the contractions were regular. They did not agree with strict time constraints around their progress that suggested they were treated differently (P9); I was taking the time of a first labour, first birth but I had the time constraints of a second birth and a VBAC (P2).

\section{The CTG}

Staff enforcement of continuous cardiotocography (CTG) and the subsequent restriction of participants' movement was the focus of this subtheme. P9 said, I wasn't able to change positions, I wasn't able to have a shower, going to the toilet I felt like hurried because you know the time pressures of taking the monitor off. In P5's case, the fetal monitor meant I couldn't leave the bed. Many participants observed the CTG to mean the midwives' role changed from that 'being with woman' to 'being with machine'. The midwife, every time the stupid monitor would beep or blip or something they'd come in and yell at me for rolling over but I was, it wasn't about facilitating the birth, it was all about the monitor (P9). Women indicated how they were not able to negotiate any flexibility around these restrictions as P9 continues her story: it became exhausting to fight every time I wanted to take the fetal monitor off ... it was all about the baby's heart beat and nothing about me as a labouring mother.

\section{Consequences}

Although it doesn't contribute to answering our specific research question, women provided a substantial amount of information on how their unsuccessful pursuit of a VBAC left them feeling, which we feel is important and relevant to include. All women expressed 
how they were grateful to have a healthy live baby but feelings of disappointment and sadness prevailed. With the reality of a vaginal birth lost, participants expressed emotions such as you feel like a bit of a failure (P15). Most women also expressed a degree of relief when the decision for a CS was made. Although disappointed they resolved the experience by focusing upon acknowledging their effort and confirming there was nothing more that could have been done. Most participants appreciated that their CS was necessary to facilitate the baby's safe birth, and as such felt there was nothing really that I could change (P8) or everything went great and the baby was healthy... so that's all you can ask for really (P7). Factors contributing to their not achieving a VBAC were regarded as being beyond their control: $I$ think I've given this a good crack and I feel like I've done everything I can (P2). In order to move forward, participants focused upon the outcomes rather than process: I think it's a horrible way to have a baby. So that part of it, not very nice but obviously when you're left with a beautiful baby boy or baby girl then it becomes a happy moment. You've just got to try and forget the rest (P13). The process of labour and birth was also rationalised by some as being not as important as they had anticipated: the birth isn't everything you know, you've got the whole everything afterwards to deal with (P14).

\section{Discussion}

The findings of this investigation are limited by the fact that they only represent the views of women attending one Australian maternity service. Nonetheless, they provide a valuable addition to the knowledge that already exists about women's perceptions of the inevitable and modifiable factors that led to them birthing as they did.

For our participants, three elements were perceived to have played a part in their planned VBAC not eventuating. These included their own lack of belief in the likelihood of achieving a VBAC, their own body's apparent physical incapacity, and a context that was predominantly unsupportive of VBAC.

\section{Uncertainty about the likelihood of achieving a VBAC}

Many of the women in our study attributed their non-elective caesarean section in part to a lack of confidence that a vaginal birth would actually eventuate for them. For some women, it was the fact of their inability to birth vaginally previously that underpinned this state of mind. For others, their belief was undermined by health professionals they encountered during pregnancy and/or labour who expressed doubt about their ability to achieve a VBAC. For some, both factors were present. Regardless of the aetiology, what seemed to have been happening for some women was a form of self-fulfilling prophesying. wherein they had come to form a belief about how their birth would turn out and then 
unwittingly effected behaviours antenatally and intrapartum, such as imposing conditions that they were unlikely to fulfil upon themselves, that made their prediction come true (Merton, 1968; Sternberg, 2011). In contrast, women whose attempt at VBAC was successful are reported to attribute the outcome in part to having a firm belief that they could give birth vaginally, and an unwavering determination to do so even in the face of others' doubt (Godden, Hauck, Hardwick, \& Bayes, 2012).

\section{The body's capacity}

Some of the informants in this study described feeling very uncertain that their body would be able to facilitate the natural birth of their baby, and the fact that a caesarean section resulted was, for them, clear proof that it was not physically possible. Our study did not seek to make any judgement about the necessity of participants' caesarean sections or about caregivers' decision-making in that regard. Perinatal statistics from comparative populations and maternity care systems, suggest that true physiological incapacity is unlikely to be the sole cause of women's inability to achieve a VBAC; a survey of 38 maternity units in the Netherlands, for example, reported a $76 \%$ VBAC attempt rate and a 54\% success rate across the included providers (Kwee, Bots, Visser, \& Bruinse, 2007).

Women who are placed with the NBAC service and wish to attempt a VBAC are carefully selected on the basis of there being no pre-existing reason why they shouldn't birth naturally. Their failure to do so in proportions greater than the subpopulation who have not had a caesarean section previously, therefore, indicates that there must be something in these women's environment or psyche that is to blame. In healthy women with a well fetus and a 'low risk' profile, that 'something' is possibly that recourse to caesarean section for labour dystocia, or 'failure to progress', is possibly more often a case of 'failure to wait' on the part of maternity caregivers (Cheng, Shaffer, Bryant, \& Caughey, 2008; Zhang et al., 2010).

In addition, women's lack of body confidence in relation to childbearing is known to extend to their perceived ability to perform other natural functions of mothering. Poor selfimage and lack of confidence can be detrimental factors in women's attempts to breastfeed successfully (Hall \& Hauck, 2007; Hauck, 2004). When added to what we know about the detrimental effect that caesarean section has on breastfeeding per se (Zanardo et al., 2010), the consequences for mothers and babies of an unsuccessful VBAC attempt which women attribute to their body failing them are concerning.

\section{Health care professionals and protocols}

The final factor that a number of our informants attributed to their unsuccessful VBAC was what they perceived as disobliging attitudes and behaviours displayed by those 
allotted to care for them in the intrapartum period. Compounding the unhelpfulness women experienced was what they described as caregivers' unquestioning 'buy in' to clinical practice guidelines which, women found, were disregarding of and inhibitory to their natural mammalian instincts in labour.

Lack of caregiver support for women's hopes, plans and needs for labour and birth is well known to feature as a stressor in women's accounts of their birth experiences. In their study investigating the experiences of women in Nigeria who failed in their attempt to achieve a VBAC, Chigbu and colleagues (2007) found, as we did, that having limits placed on options available during labour was a particularly dissatisfying aspect of the intrapartum episode for women. What is also apparent is that when women do experience stress and fear in labour, such as would occur as a result of uncertainty, derision, abandonment, inhibition and constraint, there is a detrimental effect on the progression of labour (Adams, EberhardGran, \& Eskild, 2012). Conversely, where women attempting and achieving a VBAC did feel as if the health professionals around them during labour were supportive and 'on side', they have been reported to identify this as a key attribute in their success (Godden, et al., 2012).

Our findings highlight the need for further research to illuminate aspects of providing care for women wanting a VBAC. Greater insight into the perceptions, challenges and barriers midwives face when caring for women who express a desire for a VBAC warrants further exploration. This relatively homogenous group of women all experienced an emergency CS due to a primary delay in the progress of their labour. Likewise, women planning a VBAC but who experienced an emergency CS for other reasons should also have their experience explored.

\section{Conclusion and recommendations}

The findings of this small study add a previously unexplored dimension, that of women who pursued but did not have a VBAC, to the existing body of work on women's views of why their childbearing episode unfolded as it did. Undoubtedly, some of the women in our study were truly unable to give birth vaginally. It is also possible, that some were physiologically capable of giving birth vaginally but were unable to attain their goal of a VBAC because of an interrelated set of intrinsic and exogenous factors that conspired, albeit unintentionally and unwittingly on anyone's part, against this outcome.

It is imperative that, if the unacceptably high caesarean section rates across the world are to be stemmed, maternity services need to re-examine their VBAC policies, procedures and guidelines to ensure that they reflect best evidence and require staff to be supportive of women's choice for this birth mode. Given that the risk of uterine rupture in gravid and 
labouring women who have had a previous caesarean section is known to be negligible, it is incumbent on services to demonstrate a positive organisational stance to supporting eligible women to pursue and achieve a VBAC. 


\section{References}

Adams, S., Eberhard-Gran, M., \& Eskild, A. (2012). Fear of childbirth and duration of labour: A study of 2206 women with intended vaginal delivery. British Journal of Obstetrics and Gynaecology, 119, 1238-1246.

American College of Obstetricians and Gynecologists. (2010). Vaginal birth after previous cesarean delivery: Practice bulletin no. 115. Obstetrics and Gynecology, 116 (Part 1), 450-463.

Cheng, Y., Shaffer, B. L., Bryant, A., \& Caughey, A. (2008). Length of the first stage of labour and associated perinatal outcomes in nulliparous women. Obstetrics and Gynecaology, 116(5), 1127-1135.

Chigbu, C., Enwereji, A., \& Ikeme, A. (2007). Women's experiences following failed vaginal birth after cesarean delivery. International Journal of Gynecology and Obstetrics, 99, 113-116.

Cunningham, F., Bangdiwala, S., Brown, S., Dean, T., Frederiksen, M., Rowland Hogue, C., \& Zimmet, S. (2010). National Institutes of Health Consensus Development Conference Statement: Vaginal birth after caesarean: New Insights. Obstetrics \& Gynecology, 115(6), 1279-1295.

Dahlen, H. G., \& Homer, C. S. (2011). 'Motherhood or childbirth'? A prospective analysis of vaginal birth after caesarean blogs. Midwifery. Retrieved from doi:10.1016/j.midw.2011.11.007

Fawcett, J., Tulman, L., \& Spedden, J. (1994). Responses to vaginal birth after cesarean section. Journal of Obstetrics, Gynecology and Neonatal Nursing, 23(3), 253-259.

Fenwick, J., Gamble, J., \& Mawson, J. (2003). Women's experiences of Caesarean section and vaginal birth after Caesarean: a Birthrites initiative. International Journal of Nursing Practice, 9(1), 10-17.

Godden, B., Hauck, Y., Hardwick, T., \& Bayes, S. (2012). Women's perceptions of contributory factors for successful vaginal birth after cesarean. International Journal of Childbirth, 2(2), 96-106.

Government of Western Australia: Department of Health. (2009). King Edward Memorial Hospital Next Birth After Caesarean (NBAC) Clinic. Government of Western Australia Retrieved from http://www.kemh.health.wa.gov.au/services/NBAC/index.htm.

Guise, J., Eden, K., Emeis, C., Denman, M., Marshall, N., Fu, R., \& McDonagh, M. (2010). Vaginal birth after cesarean: New insights Evidence Report/Technology Assessment series (Vol. 191). Rockville, Maryland: Oregon Evidence-based Practice Center, Oregon Health \& Science University for the Agency for Healthcare Research and Quality, U.S. Department of Health and Human Services.

Hall, W., \& Hauck, Y. (2007). Getting it right: Australian primiparas' views about breastfeeding: A quasi-experimental study. International Journal of Nursing Studies, 44, 786-795.

Hauck, Y. (2004). Factors influencing mothers' decision to breastfeed in public. Breastfeeding Review, 12(1), 15-23.

Hruban, L., Janků, P., Ventruba, P., Paúrová, L., Tápalová, V., Harastová, A., . . Jarkovský, J. (2012). Vaginal birth after previous caesarean section--outcomes analysis 20072010. Ceská Gynekologie, 77(2), 127-132.

Joyce, A., \& Hutchinson, M. (2012). Western Australia's Mothers and Babies, 2010: Twentyeighth annual report of the Western Australian Midwives' Notificiation System. Perth, Western Australia: Department of Health. 
Joyce, A., \& Tran, B. (2011). Western Australia's Mothers and Babies, 2009: Twenty-seventh Annual Report of the Western Australian Midwives' Notification System. Perth, Western Australia: Health Department of WA.

Khunpradit, S., Tavender, E., Lumbiganon, P., Laopaiboon, M., Wasiak, J., \& Gruen, R. (2011). Non-clinical interventions for reducing unnecessary caesarean section: Review. The Cochrane Library. Retrieved from http://onlinelibrary.wiley.com/doi/10.1002/14651858.CD005528.pub2/pdf

Kwee, A., Bots, M. L., Visser, G. H., \& Bruinse, H. W. (2007). Obstetric management and outcome of pregnancy in women with a history of caesarean section in the Netherlands. European Journal of Obstetric and Reproductive Biology(132), 2.

Landon, M., Leindecker, S., Spong, C., Hauth, J., Bloom, S., Varner, M., \& Gabbe, S. (2005). The MFMU cesarean registry: Factors affecting the success of labor after previous cesarean delivery. American Journal of Obstetrics and Gynecology, 193(1016-1023).

Li, Z., McNally, L., Hilder, L., \& Sullivan, E. A. (2011). Perinatal Statistics Series no. 25: Australia's mothers and babies 2009. Australian Government Retrieved from www.aihw.gov.au/WorkArea/DownloadAsset.aspx?id=10737420980.

Linacre, S. (2007). Australian Social Trends 2007. ABS Retrieved from http://www.ausstats.abs.gov.au/ausstats/subscriber.nsf/0/51EE403E951E7FDACA257 32F001CAC21/\$File/41020_Australian\%20Social\%20Trends_2007_ADJUSTED.pdf.

Lydon-Rochelle, M., Cahill, A., \& Spong, C. (2010). Birth after previous caesarean delivery: Short-term maternal outcomes. Seminars in Perinatology, 34(4), 249-247.

Macones, G., Cahill, A., Pare, E., Stamilio, D., Ratcliffe, S., Stevens, E., \& Peipert, J. (2005). Obstetric outcomes in women with two prior cesarean deliveries: Is vaginal birth after cesarean delivery a viable option? American Journal of Obstetrics and Gynecology, 192, 1223-1229.

Madaan, M., Agrawal, S., Nigam, A., Aggarwal, R., \& Trivedi, S. (2011). Trial of labour after previous caesarean section: The predictive factors affecting outcome. Journal of Obstetrics and Gynaecology, 31(3), 224-228.

Meddings, F., Phipps, F. M., Haith-Cooper, M., \& Haigh, J. (2007). Vaginal birth after caesarean section (VBAC): exploring women's perceptions. Journal of Clinical Nursing, 16(1), 160-167.

Merton, R. (1968). Social Theory and Social Structure. New York: Free Press.

National Health and Medical Research Council, Australian Research Council, \& Committee, A. V.-C. (2007). National statement on ethical conduct in human research. Canberra: Retrieved from http://www.nhmrc.gov.au/_files_nhmrc/publications/attachments/e72.pdf?q=publicati ons/synopses/_files/e72.pdf.

NSW Government. (2010). Maternity - Towards Normal Birth in NSW. Retrieved from http://www.health.nsw.gov.au/policies/pd/2010/PD2010_045.html.

Penso, C. (1994). Vaginal birth after cesarean section: an update on physician trends and patient perceptions. Current Opinions in Obstetrics and Gynecology, 6(5), 417-425.

Royal Australian and New Zealand College of Obstetricians and Gynaecologists. (2010). Planned vaginal birth after caesarean section (trial of labour) (C-Obs 38). Retrieved from http://www.ranzcog.edu.au/womens-health/statements-a-guidelines/collegestatements/441-planned-vaginal-birth-after-caesarean-section-trial-of-labour-c-obs38.html.

Royal College of Obstetricians and Gynaecologists. (2007). Green-top guideline no. 45: Birth after previous caesarean birth. Retrieved from http://www.rcog.org.uk/womenshealth/clinical-guidance/birth-after-previous-caesarean-birth-green-top-45. 
Rozen, G., Ugoni, A., \& Sheehan, P. (2011). A new perspective on VBAC: A retrospective cohort study. Women and Birth, 24, 3-9.

Schneider, Z., Whitehead, D., Elliott, D., Lobiondo-Wood, G., \& Haber, J. (2007). Nursing \& midwifery research: Methods and appraisal for evidence- based practice (3rd ed.). Sydney: Mosby Elsevier.

Sternberg, E. (2011). A self-fulfilling prophecy: linking belief to behavior. Annals of the New York Academy of Sciences, 1234, 98-99.

The Information Centre for Health and Social Care. (2012). Maternity data 2010-11. London: NHS (HESonline) Retrieved from http://www.hesonline.nhs.uk/Ease/servlet/ContentServer?siteID=1937\&categoryID=1 815.

Wells, C. E. (2010). Vaginal birth after caesarean delivery: views from the private practitioner. Seminars in Perinatology, 34(5), 345-350.

Wen, W., Rusen, I., Walker, M., Liston, R., Kramer, M., Baskett, T., \& Liu, S. (2004). Comparison of maternal mortality and morbidity between trial of labor and elective cesarean section among women with previous cesarean delivery. American Journal of Obstetrics and Gynecology, 191, 1263-1269.

World Health Organization. (1985). Appropriate technology for birth. The Lancet, 2, 436-437.

Zanardo, V., Svegliado, G., Cavallin, F., Giustardi, A., Cosmi, E., Litta, P., \& Trevisanuto, D. (2010). Elective Cesarean Delivery: Does It Have a Negative Effect on Breastfeeding? Birth, 37, 275-279.

Zhang, L., Landy, H. J., Branch, D. W., Burkman, R., Haberman, S., Gregory, K. D., . . Consortium on Safe Labor. (2010). Contemporary patterns of spontaneous labor with normal neonatal outcomes. Obstetrics and Gynecology, 116(6), 1281-1287. 
Table 1. Recent labour and birth information

\begin{tabular}{|l|c|}
\hline Variable & Number of participants \\
\hline Labour onset & \\
\hline Spontaneous & 7 \\
Spontaneous + augmented & 6 \\
Induced & 2 \\
Total & 15 \\
\hline Length of labour (hrs) & \\
\hline$<6$ & 1 \\
$6-15$ & 9 \\
$>15$ & 5 \\
Total & 15 \\
\hline Cervical dilation at time of caesarean (cm) & \\
\hline First stage & 3 \\
$0-3$ (Latent stage) & 10 \\
$4-7$ (Active stage) & 0 \\
$8-10$ (Transition) & 2 \\
Second stage (full dilatation) & 15 \\
Total & \\
\hline Pain relief (combinations used) & $1 / 15$ \\
\hline Water (bath or shower) & $6 / 15$ \\
Nitrous gas & $5 / 15$ \\
Intramuscular narcotic (Morphine) & $15 / 15$ \\
Epidural & $15 / 15$ \\
\hline Birth weight (kg) & 15 \\
\hline$<3.37$ (Australian average) & 15 \\
3.37- 4 & 6 \\
> 4 & 15 \\
Total & \\
\hline APGAR scores at 1 minute after birth & \\
\hline$<7$ & \\
$8-10$ & \\
Total & \\
APGAR scores at 5 minutes >8 & \\
\hline Other: & \\
History of previous miscarriage or termination & \\
Employed a Doula for current labour support & \\
Previous pregnancy under private obstetric care & \\
\hline
\end{tabular}


Table 2. Risk factors for unsuccessful VBAC (RCOG, 2007)

\begin{tabular}{|l|c|}
\hline Variable & Number of participants \\
$\mathbf{N = 1 5}$
\end{tabular}

Kappel, B. et al (1987). Short stature in Scandinavian women: an obstetrical risk factor. Acta Obstet Gynecol Scand, 66(2):153-8. 
Table 3. Factors perceived by women for not achieving VBAC

\section{Themes and subthemes}

Tentative commitment, lingering doubts

My body failed me

Compromised by a longer that tolerable labour

Unable to effectively self-advocate in a climate of power struggling and poor support

The inflexibility of hospital processes

Restrictive policies

The CTG 